\title{
Opposing trends in the prevalence of health professional-diagnosed asthma by sex: A Canadian National Population Health Survey study
}

\author{
S Ghosh $\mathrm{MSc}^{1}$, P Pahwa $\mathrm{PhD}^{1,2}$, D Rennie $\mathrm{PhD}^{1,3}, \mathrm{HH}$ McDuffie $\mathrm{PhD}^{1}$
}

\begin{abstract}
S Ghosh, P Pahwa, D Rennie, HH McDuffie. Opposing trends in the prevalence of health professional-diagnosed asthma by sex: A Canadian National Population Health Survey study. Can Respir J 2008;15(3):146-152.
\end{abstract}

BACKGROUND: The prevalence of asthma is on the rise worldwide, with large variations in prevalence existing between and within countries. Little is known regarding the variation in asthma prevalence in adults living in rural and urban settings.

OBJECTIVES: Using questionnaire data from the Canadian National Population Health Survey, the prevalence of asthma at four time periods (1994/1995 [cycle 1], 1996/1997 [cycle 2], 1998/1999 [cycle 3] and 2000/2001 [cycle 4]) was compared between rural and urban populations stratified by sex, smoking status and age group. Asthma was defined as a positive response to the question: "Do you have asthma diagnosed by a health professional?"

METHODS: To account for the complexity of the survey design, the bootstrap method was used to calculate prevalences and 95\% CIs.

RESULTS: Overall, the prevalence of asthma increased from $7.3 \%$ (cycle 1) to $7.5 \%$ (cycle 4). After stratifying by sex, the asthma prevalence decreased among men, but in women, there was a steady increase. Asthma prevalence increased for both the rural population and the urban population. After stratifying each cycle by sex and location (rural or urban), both rural and urban men showed a decrease in asthma prevalence. On dividing according to age groups ( 0 to 14 years, 15 to 34 years, 35 to 64 years, and 65 years and older), the prevalence of asthma was greatest in the 15- to 34-year age group of urban and rural women.

CONCLUSIONS: Asthma prevalence increased among rural and urban women. The prevalence of asthma was highest among female smokers and male nonsmokers when stratified by smoking status. Based on these findings, the rate of increase in asthma prevalence is different for men and women.

Key Words: Asthma prevalence; Bootstrap; Complex survey design; Rural; Smoking; Urban; Women

$\mathrm{T}$ he prevalence of asthma in both adults and children is on the rise worldwide. Approximately 10\% of adults and 35\% of children have asthma. There is an abundance of literature on the increase in asthma rates among children in many western countries. However, research is somewhat limited in adults. One of the reasons may be that adult asthma is often confused with other smoking-related diseases (1), such as chronic obstructive pulmonary disease. Studies conducted around the globe have examined the asthma prevalence among adults in North
Tendances divergentes quant à la prévalence de l'asthme diagnostiqué par un professionnel de la santé selon le sexe : Enquête nationale sur la santé de la population

HISTORIQUE : La prévalence de l'asthme est en hausse à l'échelle mondiale, mais il existe d'importantes variations quant à sa prévalence à l'intérieur de chaque pays et entre eux. On dispose de peu de données au sujet des variations de la prévalence de l'asthme chez les adultes vivant en milieu rural et urbain.

OBJECTIF : À l'aide de données provenant des questionnaires de l'Enquête nationale sur la santé de la population du Canada, la prévalence de l'asthme a été comparée entre les populations rurales et urbaines stratifiées selon le sexe, le statut à l'égard du tabagisme et l'âge, pour quatre périodes (1994-1995 [cycle 1], 1995-1997 [cycle 2], 1998-1999 [cycle 3] et 2000-2001 [cycle 4]). L'asthme se définissait par une réponse affirmative à la question : "Souffrez-vous d'un asthme qui a été diagnostiqué par un professionnel de la santé ?».

MÉTHODES : Pour tenir compte de la complexité du modèle de l'enquête, la méthode d'auto-amorçage a été utilisée pour calculer les prévalences et les IC à $95 \%$.

RÉSULTATS : Dans l'ensemble, la prévalence de l'asthme est passée de $7,3 \%$ (cycle 1 ) à 7,5 \% (cycle 4). Après stratification selon le sexe, la prévalence de l'asthme a diminué chez les hommes, mais a régulièrement augmenté chez les femmes. La prévalence de l'asthme a augmenté dans les populations rurales et urbaines. Après stratification de chaque cycle selon le sexe et le milieu rural ou urbain, on a observé une baisse de la prévalence de l'asthme chez les hommes des régions rurales et urbaines. Lors de la répartition selon les groupes d'âge ( 0 à 14 ans, 15 à 34 ans, 35 à 64 ans et 65 et plus), la prévalence de l'asthme a été la plus forte chez les femmes de 15 à 34 ans des milieux ruraux et urbains.

CONCLUSION : La prévalence de l'asthme a augmenté chez les femmes des milieux ruraux et urbains. La prévalence de l'asthme a été la plus forte chez les femmes fumeuses et les hommes non fumeurs lors de la stratification selon le statut à l'égard du tabagisme. À partir de ces résultats, on conclut que les hommes et les femmes présentent un taux différent d'augmentation de la prévalence de l'asthme.

American (2-4), Oceanic (5) and European (6-8) countries. The European Community Respiratory Health Survey (ECRHS), an international comparative study in adults, found that asthma prevalence was most common in western countries, and was higher in developed countries due to increasing urbanization (9). However, little is known about the factors associated with increasing asthma rates in adults.

Noncancerous respiratory diseases are common and costly diseases, and asthma plays a major role in them. Respiratory

${ }^{1}$ Canadian Centre for Health and Safety in Agriculture; ${ }^{2}$ Department of Community Health and Epidemiology; ${ }^{3}$ College of Nursing, University of Saskatchewan, Saskatoon, Saskatchewan

Correspondence: Ms Sunita Ghosh, Suite 104 - 2711 112th Street, Edmonton, Alberta T6J 4M1. Telephone 780-634-8500, fax 780-432-8425, e-mail sunita.ghosh@gmail.com 
disease, which can cause hospitalization and death, is the third most serious health problem in Canada (10). In Canada, the direct and indirect health care cost of respiratory diseases, excluding lung cancer, for the year 1993 was approximately $9.4 \%$ of total cost (10). Such diseases are a burden to any country, and steps need to be taken as a precautionary measure. More studies in adults are needed to determine the factors that result in higher prevalences of asthma. Longitudinal studies are an option, because in these studies, an individual can be followed over time to determine the risk factors resulting in asthma.

A few cross-sectional studies $(4,11)$ have been conducted to compare the health of rural populations with urban populations. Boulet et al (11) reported a rise in mortality (by approximately 28.6\%) due to increasing asthma in Quebec adults during the period 1975 to 1985 . They also concluded that asthma mortality increased in women in both rural and urban areas, more than among men. Senthilselvan (12) studied ruralurban differences in asthma hospitalizations during the period from 1970 to 1989 , and the prevalence of physician-diagnosed asthma during the period from 1991 to 1998 (4). Both studies concluded that the prevalence of asthma was higher among urban populations than among rural populations.

The relationship between cigarette smoking and asthma has also been investigated in many Canadian studies (13-17). To our knowledge, no research on asthma prevalence or smoking status, or comparisons of the health of rural-urban populations, has been conducted in Canada. Using the National Population Health Survey (NPHS) data set, the variation of asthma prevalence between rural and urban populations was assessed in four different time periods.

The objective of the present study was to estimate the prevalences of self-reported health professional-diagnosed asthma in Canada across four cycles of the NPHS data stratified by sex, age group and location (rural or urban). Asthma prevalences among smokers, ex-smokers and nonsmokers were also compared.

\section{METHODS}

The present study was based on longitudinal data from four cycles of the NPHS questionnaire data. The prevalence of asthma was determined separately for each of the four cycles. The target population included household residents in all 10 provinces. Individuals living on Indian reserves or Crown land, residents of health care institutions, full-time members of the Canadian Armed Forces, and residents in remote areas of Ontario and Quebec were not included.

The sample design was a stratified, multistage design (18) for all provinces except Quebec, which was based on a twostage sample design. At each stage in the sampling designs, units were subsampled from the higher hierarchical level of procedure. For the NPHS, at the first stage, the province of Canada was subdivided into three major areas (major urban centres, urban towns and rural areas). From these, homogeneous strata were formed, based on socioeconomic status and geographic location. In the second stage, clusters were formed from the strata. In the third stage, households were selected at random from the clusters, and one individual was chosen from each household to form the longitudinal panel.

The NPHS redesigned the sampling methodology developed for the Labour Force Survey (LFS) (19). The NPHS initially had a target sample size of approximately 19,600 households.
However, a total of 20,095 participants were selected in 1994/1995 (cycle 1) to form the panel. These participants completed at least the general component of the questionnaire in cycle 1 . A total of 17,276 participants responded; henceforth, for cycle 2 onwards, the longitudinal panel members consisted of these participants. The longitudinal sample was not renewed over time, and it remained the same for all cycles. This same group of individuals was surveyed in 1996/1997 (cycle 2), 1998/1999 (cycle 3) and 2000/2001 (cycle 4), and will be studied every two years in the future as well.

Asthma was self-reported based on any long-term conditions that had lasted or were expected to last six months or longer, and that had been diagnosed by a health professional (19). The question asked was "Do you have asthma diagnosed by a health professional?" (19). Rural areas included the populations living outside places of 1000 people or more (20-22). "An area that has a minimum population concentration of 1000 or more, and a population density of at least 400 per square kilometer, based on previous census counts" (22) was defined as an urban area.

The total number of respondents who answered in affirmation to the asthma question formed the numerator, and the total population at the time of study formed the denominator. All of the respondents who chose not to answer this question were excluded from the analysis. The prevalence of asthma was estimated separately for each cycle using the same prevalence formula. Age-specific, sex-specific and location-specific prevalence values were computed for each cycle.

Current smokers were defined as those respondents who answered yes to daily and occasional smoking to the question: "At the present time do you smoke cigarettes daily, occasionally or not at all?" Ex-smokers were those respondents who answered no to the above question and yes to the question: "Have you ever smoked cigarettes at all?" Nonsmokers were those respondents who answered no to both questions stated above. Responses were coded as missing if the respondents chose not to answer or not applicable to the smoking questionnaire. The smoking questionnaire excluded respondents younger than 15 years of age.

The sampling design of the NPHS data is based on a complex survey design. The statistical methods used should account for the survey design. Failure to account for all of the three features of survey design can result in biased estimates (23). The bootstrap method was used, which is an approximation method for variance estimation, because it was able to account for the sample design information. For the present analysis, 500 bootstrap weights were produced to calculate the point estimate, as well as to calculate the SE and 95\% CI (18). The Bootvar program, developed by Statistics Canada, uses the bootstrap method to compute the variances (19). SAS version 8.2 (SAS Institute, USA) was used to carry out the statistical analysis. Means \pm SEs were computed for the continuous variable age, and proportions were computed for the categorical variable smoking status stratified by sex and location for each cycle. The distribution of the population for each province and cycle was calculated for each sex and location (rural or urban). The prevalence of asthma was calculated for rural and urban men and women, for each cycle separately, and for each age group ( 0 to 14 years, 15 to 34 years, 35 to 64 years, and 65 years and older). Asthma prevalence was also calculated for smokers, ex-smokers and nonsmokers in each cycle. 
TABLE 1

Weighted mean \pm SE age (years) of men and women stratified by location (rural or urban) for each cycle

\begin{tabular}{|c|c|c|c|c|c|c|c|c|}
\hline \multirow[b]{2}{*}{ Location } & \multicolumn{2}{|c|}{ Cycle 1} & \multicolumn{2}{|c|}{ Cycle 2} & \multicolumn{2}{|c|}{ Cycle 3} & \multicolumn{2}{|c|}{ Cycle 4} \\
\hline & Men & Women & Men & Women & Men & Women & Men & Women \\
\hline Rural & $36.2 \pm 0.5$ & $35.1 \pm 0.5$ & $36.1 \pm 0.2$ & $35.7 \pm 0.5$ & $38.8 \pm 0.5$ & $37.9 \pm 0.5$ & $39.8 \pm 0.5$ & $39.4 \pm 0.5$ \\
\hline Urban & $33.8 \pm 0.3$ & $36.2 \pm 0.3$ & $35.7 \pm 0.3$ & $38.2 \pm 0.3$ & $38.0 \pm 0.3$ & $40.0 \pm 0.3$ & $38.4 \pm 0.3$ & $41.1 \pm 0.3$ \\
\hline Total & $34.2 \pm 0.2$ & $36.0 \pm 0.2$ & $35.8 \pm 0.2$ & $37.8 \pm 0.2$ & $37.3 \pm 0.2$ & $39.3 \pm 0.2$ & $38.7 \pm 0.3$ & $40.8 \pm 0.3$ \\
\hline
\end{tabular}

Cycle 1 of the National Population Health Survey was conducted in 1994/1995, cycle 2 in 1996/1997, cycle 3 in 1998/1999 and cycle 4 in 2000/2001

TABLE 2

Weighted percentage of smoking status by location for each cycle $(n=28,318,308)^{*}$

\begin{tabular}{|c|c|c|c|c|}
\hline Smoking status & Cycle 1 & Cycle 2 & Cycle 3 & Cycle 4 \\
\hline \multicolumn{5}{|l|}{ Smokers, \% } \\
\hline Rural & 4.14 & 3.80 & 4.00 & 3.74 \\
\hline Urban & 19.40 & 18.15 & 15.61 & 14.56 \\
\hline \multicolumn{5}{|l|}{ Ex-smokers, \% } \\
\hline Rural & 4.21 & 4.03 & 5.21 & 5.60 \\
\hline Urban & 19.65 & 19.48 & 20.49 & 21.12 \\
\hline \multicolumn{5}{|l|}{ Nonsmokers, \% } \\
\hline Rural & 5.19 & 5.25 & 5.11 & 5.09 \\
\hline Urban & 27.70 & 26.89 & 23.78 & 21.88 \\
\hline Missing ${ }^{\dagger}$ & 19.71 & 22.13 & 25.80 & 28.01 \\
\hline
\end{tabular}

Weighted percentage of smoking status by sex for each cycle $(n=28,318,308)^{*}$

\begin{tabular}{|c|c|c|c|c|}
\hline Smoking status & Cycle 1 & Cycle 2 & Cycle 3 & Cycle 4 \\
\hline \multicolumn{5}{|l|}{ Smokers, \% } \\
\hline Men & 12.09 & 11.60 & 10.15 & 9.55 \\
\hline Women & 11.45 & 10.35 & 9.46 & 8.75 \\
\hline \multicolumn{5}{|l|}{ Ex-smokers, \% } \\
\hline Men & 12.78 & 13.08 & 13.97 & 14.23 \\
\hline Women & 11.08 & 10.70 & 11.73 & 12.49 \\
\hline \multicolumn{5}{|l|}{ Nonsmokers, \% } \\
\hline Men & 14.16 & 13.58 & 12.18 & 11.18 \\
\hline Women & 18.73 & 18.56 & 16.71 & 15.79 \\
\hline Missing ${ }^{\dagger}$ & 19.71 & 22.13 & 25.80 & 28.01 \\
\hline
\end{tabular}

*Represents the target population of 1994/1995; †Includes nonapplicable (smoking-related question asked to respondents 15 years and older) and unstated categories

\section{RESULTS}

The response rates were $86 \%$ for cycle $1,93.6 \%$ for cycle 2 , $88.9 \%$ for cycle 3 and $84.8 \%$ for cycle 4 . The response rate for cycle 1 was based on 20,095 participants selected to form the panel. For the other cycles, the response rates were based on 17,276 panel members. The attrition rates were $9.3 \%$ at the end of cycle $2,6.7 \%$ in cycle 3 and $7.1 \%$ at the end of cycle 4 . Complete response included participants who provided a complete response to the interview in each of the four cycles, or were deceased or institutionalized. A total of 13,582 participants $(78.6 \%)$ had complete responses in all four cycles. The participants with partial or no responses were regarded as missing or incomplete. The present analysis included all of the 17,276 participants, regardless of the response pattern.

The mean age of 17,276 participants, stratified by sex and location for each cycle, is provided in Table 1. In general, female participants were significantly older than their male

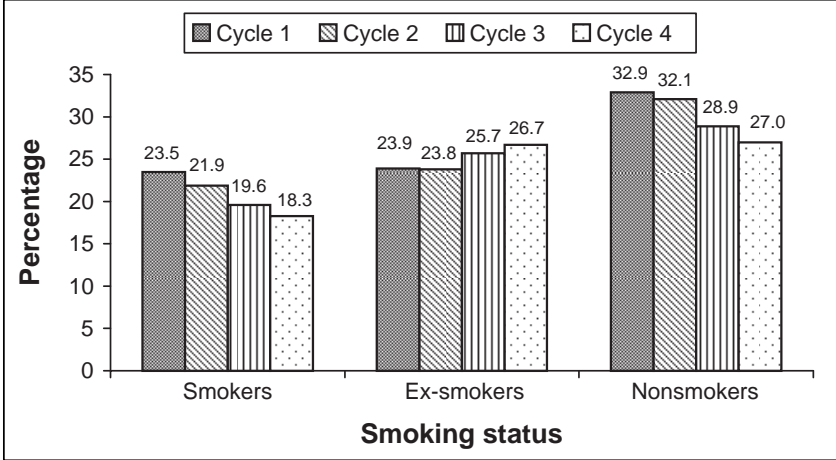

Figure 1) Participants stratified based on smoking status and cycle of participation

counterparts. Rural participants were older than urban participants. Stratification by sex and location showed that urban men were younger than rural and urban women, as well as rural men, in all four cycles. Rural men were older than urban men, and the opposite was observed in women (Table 1).

Weighted percentages of smoking status for each cycle were studied separately by location and sex (Table 2). The denominator of the percentage was the 1994/1995 target Canadian population of 28,318,308 people. The percentages of the respondents who did not provide an answer to the smoking questionnaire are also presented. The nonresponders to this question were those who were younger than 15 years of age and/or those who chose not to answer the question. The percentage of female nonsmokers was higher than male nonsmokers in all four cycles, and the percentage of both smokers and ex-smokers was higher in men than women. The number of smokers, ex-smokers and nonsmokers were higher in the urban population than in the rural population. The overall percentage of smokers decreased from $23.5 \%$ (cycle 1) to $18.3 \%$ (cycle 4), and the overall percentage of nonsmokers decreased from $32.9 \%$ (cycle 1 ) to $27.0 \%$ (cycle 4 ). The overall percentage of ex-smokers showed an increase from $23.9 \%$ (cycle 1 ) to $26.7 \%$ (cycle 4) (Figure 1).

The prevalence of asthma based on the response to the question "Do you have asthma diagnosed by a health professional?" is provided in Table 3. Overall, asthma prevalence increased from $7.3 \%$ in cycle 1 to $7.5 \%$ in cycle 4 , although the change was not statistically significant. Women showed an increase in asthma prevalence from $7.2 \%$ (cycle 1) to $8.1 \%$ (cycle 4), while men showed a decrease from $7.3 \%$ (cycle 1) to $6.9 \%$ (cycle 4) (Figure 2). None of these changes in asthma prevalence from cycle 1 through cycle 4 were significant. Further stratification by sex and location showed an increase in asthma prevalence among rural and urban women, while the opposite was observed for rural and urban men (Table 3). 
TABLE 3

Prevalence of health professional-diagnosed asthma for each cycle stratified by sex and location

\begin{tabular}{|c|c|c|c|c|c|c|c|c|c|c|c|c|}
\hline \multirow[b]{2}{*}{ Location } & \multicolumn{3}{|c|}{ Cycle 1} & \multicolumn{3}{|c|}{ Cycle 2} & \multicolumn{3}{|c|}{ Cycle 3} & \multicolumn{3}{|c|}{ Cycle 4} \\
\hline & Men & Women & Total & Men & Women & Total & Men & Women & Total & Men & Women & Total \\
\hline $\begin{array}{l}\text { Rural, \% } \\
\qquad(95 \% \mathrm{Cl})\end{array}$ & $\begin{array}{c}6.4 \\
(4.8-7.9)\end{array}$ & $\begin{array}{c}6.6 \\
(5.1-8.0)\end{array}$ & $\begin{array}{c}6.5 \\
(5.3-7.6)\end{array}$ & $\begin{array}{c}6.0 \\
(4.5-7.6)\end{array}$ & $\begin{array}{c}7.2 \\
(5.5-8.8)\end{array}$ & $\begin{array}{c}6.6 \\
(5.4-7.7)\end{array}$ & $\begin{array}{c}5.3 \\
(3.9-6.7)\end{array}$ & $\begin{array}{c}7.4 \\
(5.9-9.0)\end{array}$ & $\begin{array}{c}6.3 \\
(5.3-7.4)\end{array}$ & $\begin{array}{c}5.8 \\
(4.4-7.2)\end{array}$ & $\begin{array}{c}7.7 \\
(6.2-9.3)\end{array}$ & $\begin{array}{c}6.7 \\
(5.7-7.7)\end{array}$ \\
\hline $\begin{array}{l}\text { Urban, \% } \\
\qquad(95 \% \mathrm{Cl})\end{array}$ & $\begin{array}{c}7.5 \\
(6.6-8.4)\end{array}$ & $\begin{array}{c}7.3 \\
(6.5-8.1\end{array}$ & $\begin{array}{c}7.4 \\
(6.8-8.0)\end{array}$ & $\begin{array}{c}7.3 \\
(6.4-8.1)\end{array}$ & $\begin{array}{c}7.8 \\
(7.0-8.6)\end{array}$ & $\begin{array}{c}7.5 \\
(7.0-8.1)\end{array}$ & $\begin{array}{c}7.4 \\
(6.5-8.3)\end{array}$ & $\begin{array}{c}8.0 \\
(7.2-8.9)\end{array}$ & $\begin{array}{c}7.7 \\
(7.2-8.3)\end{array}$ & $\begin{array}{c}7.2 \\
(6.3-8.1)\end{array}$ & $\begin{array}{c}8.2 \\
(7.4-9.0)\end{array}$ & $\begin{array}{c}7.7 \\
(7.1-8.3)\end{array}$ \\
\hline $\begin{array}{l}\text { Total, \% } \\
(95 \% \mathrm{Cl})\end{array}$ & $\begin{array}{c}7.3 \\
(6.5-8.1)\end{array}$ & $\begin{array}{c}7.2 \\
(6.5-7.9)\end{array}$ & $\begin{array}{c}7.3 \\
(6.7-7.8)\end{array}$ & $\begin{array}{c}7.0 \\
(6.3-7.8)\end{array}$ & $\begin{array}{c}7.7 \\
(7.0-8.4)\end{array}$ & $\begin{array}{c}7.4 \\
(6.9-7.9)\end{array}$ & $\begin{array}{c}7.0 \\
(6.3-7.8)\end{array}$ & $\begin{array}{c}7.9 \\
(7.2-8.7)\end{array}$ & $\begin{array}{c}7.5 \\
(7.0-8.0)\end{array}$ & $\begin{array}{c}6.9 \\
(6.2-7.7)\end{array}$ & $\begin{array}{c}8.1 \\
(7.4-8.9)\end{array}$ & $\begin{array}{c}7.5 \\
(7.0-8.0)\end{array}$ \\
\hline
\end{tabular}

Cycle 1 of the National Population Health Survey was conducted in 1994/1995, cycle 2 in 1996/1997, cycle 3 in 1998/1999 and cycle 4 in 2000/2001

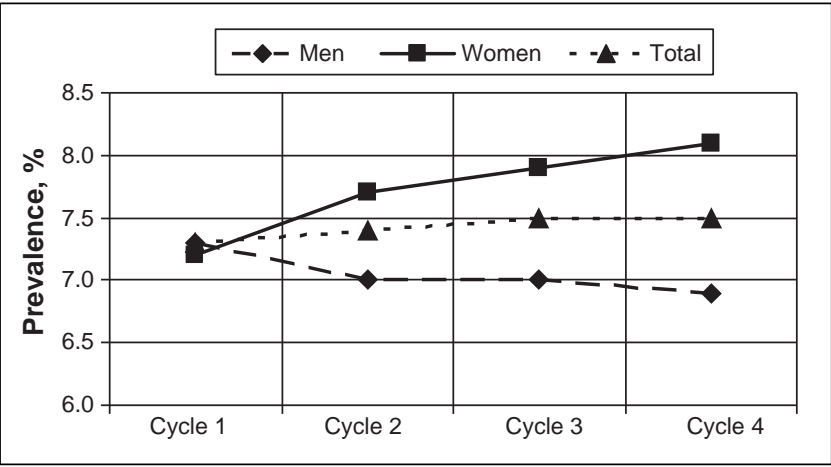

Figure 2) Overall asthma prevalence and prevalence stratified by sex. Prevalences are representative of the 1994/1995 population who reported that they had been diagnosed with asthma by a health professional. No significant differences were observed between asthma prevalences

Asthma was more prevalent in urban than rural residents. When stratified by location, rural men showed the most decline in asthma prevalence from cycle 1 to cycle 4 , followed by urban men. However, both urban and rural women showed an increase in asthma prevalence over time (Figure 3).

Because no statistical difference was found in the overall prevalence, further analysis was conducted by stratifying by age groups (Table 4). Asthma prevalence was highest in urban men younger than 15 years of age compared with rural men, rural women and urban women. The prevalence of asthma was higher in urban men than rural men, and this difference was significant $(\mathrm{P}<0.05)$ in cycle 2 in the 15 - to 34 -year age group. A similar significant difference was noticed in women in cycle 2 . In the same age group, asthma prevalence was observed to be higher in urban women than urban men, and this was significant in cycle $4(\mathrm{P}<0.05)$. In the 35 - to 64-year age group, for all cycles, the prevalence of asthma was higher in women than men in both rural and urban locations. In the same age group, the prevalence of asthma among urban women increased significantly from $4.8 \%$ in cycle 1 to $8.1 \%$ in cycle 4 $(\mathrm{P}<0.05)$. When studying the differences between sexes, urban women showed a higher prevalence than urban men, and this was statistically significant in cycle 2. A similar trend was observed in rural men and women. For cycle 3, the prevalence in rural women was significantly higher than rural men $(\mathrm{P}<0.05)$. In the 65-year and older age group, asthma prevalence was higher in rural men $(6.6 \%$ in cycle 1$)$ and urban women $(5.4 \%$ in cycle 1$)$, and this, too, increased over time ( $7.7 \%$ in cycle 4 in rural men, and $7.8 \%$ in cycle 4 in urban

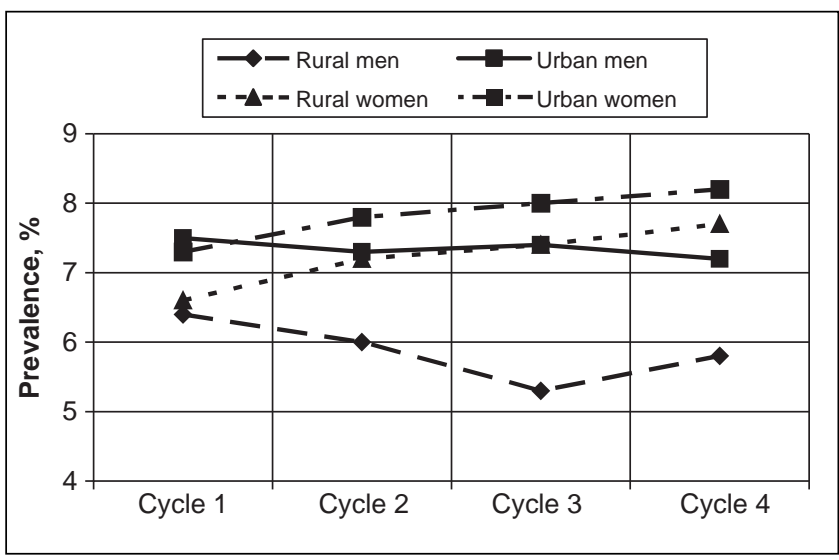

Figure 3) Asthma prevalence stratified by sex and location. Prevalences are representative of the 1994/1995 population who reported that they had been diagnosed with asthma by a health professional. No significant differences were observed between asthma prevalences for any of the categories

women). However, the increase in prevalence over time was not significantly different.

Asthma prevalence among smokers, ex-smokers and nonsmokers is presented in Table 5. These results are based on NPHS participants who were older than 15 years of age. The prevalence of asthma stratified by smoking status was studied separately for sex and location. The rural and urban differences among smokers, ex-smokers and nonsmokers for cycle 1 through cycle 4 were not statistically significant. The prevalence of asthma was higher among urban smokers, ex-smokers and nonsmokers than among rural participants, except for during cycle 4, when asthma prevalence was higher among rural ex-smokers than among urban ex-smokers.

On studying asthma prevalence stratified by sex and smoking status, prevalence was higher in female smokers and ex-smokers than men in all four cycles. The difference in the prevalence among smokers was statistically significant at the $\mathrm{P}<0.05$ level for all cycles except cycle 2. Among ex-smokers, the difference was significant only in cycle 3 and 4 . The prevalence of asthma among nonsmokers was more prevalent in men than women; however, no statistical difference was observed.

Within the urban location category, the prevalence of asthma significantly increased from cycle 1 to cycle $4(\mathrm{P}<0.05)$ for all three smoking categories. The prevalence also increased for rural participants, but no statistical difference was found. 
TABLE 4

Health professional-diagnosed asthma prevalence for each cycle stratified by age, sex and location

\begin{tabular}{|c|c|c|c|c|c|c|c|c|}
\hline \multirow[b]{2}{*}{ Age group } & \multicolumn{2}{|c|}{ Cycle 1} & \multicolumn{2}{|c|}{ Cycle 2} & \multicolumn{2}{|c|}{ Cycle 3} & \multicolumn{2}{|c|}{ Cycle 4} \\
\hline & Men & Women & Men & Women & Men & Women & Men & Women \\
\hline \multicolumn{9}{|l|}{$0-14$ years } \\
\hline Urban & $14.0(11.3-16.7)$ & $10.4(7.6-13.1)$ & $13.8(10.4-17.1)$ & $8.9(6.3-11.6)$ & $15.6(11.6-19.6)$ & $11.4(8.1-14.8)$ & $17.5(12.6-22.3)$ & $10.7(7.8-13.6)$ \\
\hline \multicolumn{9}{|l|}{$15-34$ years } \\
\hline Rural & $4.9(2.6-7.2)$ & $6.5(3.7-9.4)$ & $4.2^{*}(2.0-6.5)$ & $6.8^{*}(3.2-10.1)$ & $8.6(4.9-12.6)$ & $11.0(7.3-14.8)$ & $6.0(3.1-8.9)$ & $12.3(8.2-16.4)$ \\
\hline \multicolumn{9}{|l|}{$35-64$ years } \\
\hline Rural & $4.4(2.3-6.6)$ & $6.2(3.8-8.6)$ & $4.9(2.6-7.2)$ & $7.7(5.1-10.3)$ & $3.3(1.8-4.8)$ & $7.5(5.2-9.8)$ & $5.2(3.4-7.0)$ & $7.4(5.1-9.8)$ \\
\hline Urban & $3.8(2.8-4.9)$ & $4.8^{*}(3.9-5.7)$ & $4.5(3.3-5.6)$ & $6.7(5.7-7.8)$ & $5.8(4.5-7.2)$ & $7.5(6.3-8.7)$ & $6.5(5.0-8.0)$ & $8.1^{*}(7.0-9.2)$ \\
\hline \multicolumn{9}{|l|}{$\geq 65$ years } \\
\hline Rural & $6.6(2.4-10.8)$ & $3.9(1.7-6.2)$ & $5.4(2.1-8.6)$ & $3.8(1.5-6.1)$ & $7.2(3.1-11.3)$ & $4.6(1.6-7.6)$ & $7.7(3.6-11.8)$ & $6.5(2.6-10.4)$ \\
\hline
\end{tabular}

All values are given as per cent (95\% Cl). Cycle 1 of the National Population Health Survey was conducted in 1994/1995, cycle 2 in 1996/1997, cycle 3 in 1998/1999 and cycle 4 in 2000/2001. ${ }^{*} P<0.05$

TABLE 5

Physician-diagnosed asthma prevalence in smokers, ex-smokers and nonsmokers in each cycle stratified by sex and location

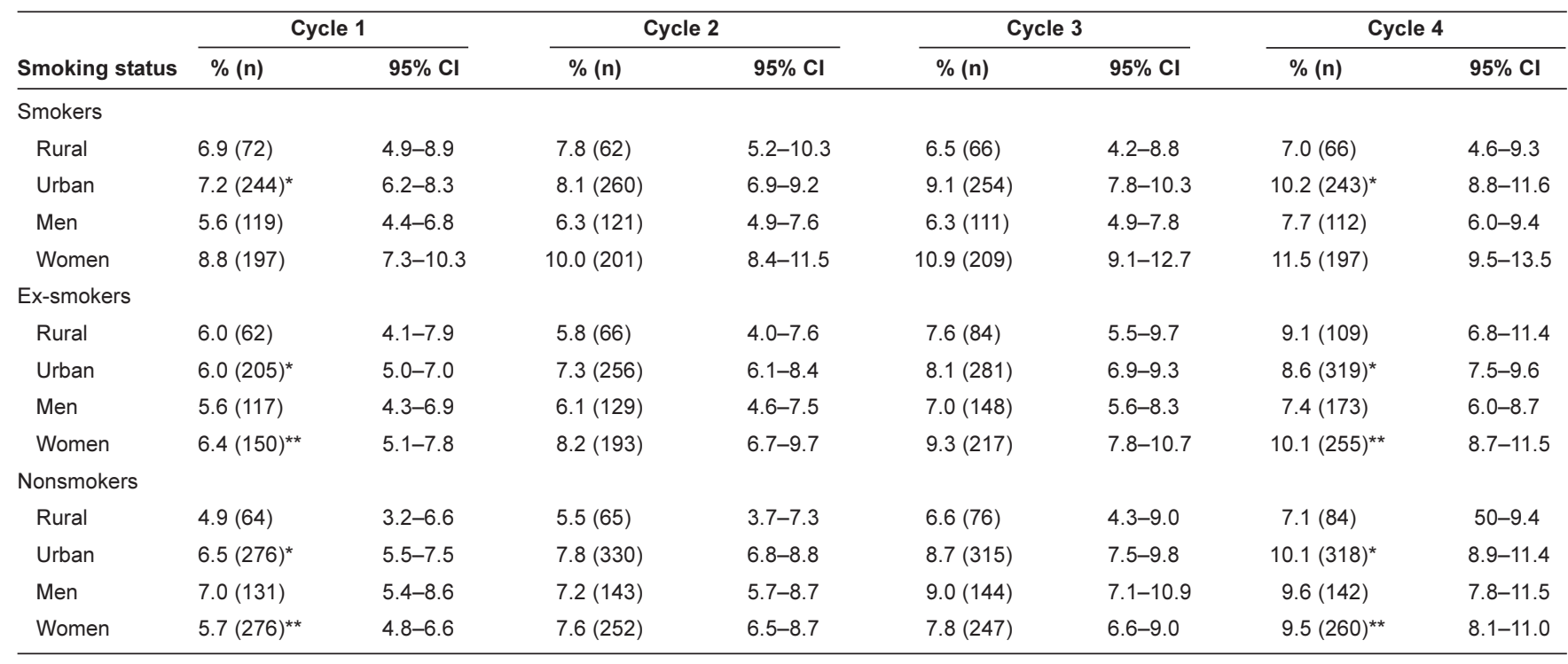

Cycle 1 of the National Population Health Survey was conducted in 1994/1995, cycle 2 in 1996/1997, cycle 3 in 1998/1999 and cycle 4 in 2000/2001. ${ }^{*} P<0.05$, ${ }^{*} P<0.001$

Within sex, an increase in asthma prevalence among men and women was observed over time for all three smoking categories. The increase in prevalence from cycle 1 through cycle 4 was statistically significant for ex-smoking and nonsmoking women $(\mathrm{P}<0.001)$.

\section{DISCUSSION}

These findings, based on longitudinal NPHS data, suggest that overall asthma prevalence increased among all age groups and steadily increased from cycle 1 to cycle 4 . The increase was more prevalent among both rural and urban Canadian women than men. In men, a totally opposite trend was noticed. There was a decrease in asthma prevalence from $7.3 \%$ in cycle 1 to $6.9 \%$ in cycle 4 . This finding is well supported by other studies conducted around the world. A Norwegian asthma survey study (24) found that the crude prevalence of asthma more than tripled in women and more than doubled in men during the study period of 26 years. Boulet et al (11) also reported that asthma prevalence was higher among women than men. When we studied the asthma prevalence after stratifying sex by age groups, asthma prevalence steadily increased in women among all age groups, but in men, the trend was mixed. The prevalence was higher and more pronounced in younger men (younger than 15 years of age) and in older women aged 15 to 64 years. Similar results have been obtained in several other studies, which have shown that asthma prevalence is associated with age and sex (25-28). The reason for this reversal during and after puberty may be attributed to hormonal changes, or due to narrowing of airway calibre in women as they grow older, while the opposite occurs in men $(25,29)$. We found rural and urban differences in asthma prevalence in both sexes. These differences in rural and urban men in the age group from 15 to 
34 years were statistically significant. There were significant differences in asthma prevalence between rural men and women, and between urban men and women. These results were interesting, because there are not many comparative studies conducted longitudinally that have investigated the prevalence of asthma among rural and urban populations. Two cross-sectional studies reported that asthma prevalence was higher among rural populations $(30,31)$, and another suggested the opposite (4). Our study found that the prevalence of asthma was higher in urban residents than rural residents. One reason may be that living in a rural area or on a farm in the younger years is protective against developing asthma $(4,32)$. Another reason for the higher prevalence of asthma in urban residents may be air pollution in urban areas (30). These are some of the rural-urban differences that need further investigation.

The relationship between asthma and smoking is still not clear (33). Some studies $(34,35)$ have shown that there is a positive association between smoking and asthma, while other studies have found no associations $(36,37)$, weak associations $(38,39)$ or an inverse relationship $(40)$. A cross-sectional study using NPHS data collected in the year 1994/1995 showed that smoking was associated with asthma in women but not in men (16). Further analysis of the longitudinal NPHS data set in two time periods (1994/1995 and 1996/1997) showed that this result remained unchanged (15). One of the reasons for the higher prevalence in female smokers may be that women are more susceptible to irritation of the lung from smoking, which causes an increase in asthma symptoms (41). 'Unhealthy' respondents (subjects with more respiratory symptoms) are less likely than healthy subjects to start smoking (42). This may be one of the reasons for the higher prevalence of asthma in male nonsmokers. The prevalence of asthma among smokers and nonsmokers were more prominent in urban residents than rural residents. Higher stress levels and lack of open spaces, compared with their rural counterparts, may be possible reasons for the higher asthma prevalence in smokers living in urban areas. Environmental factors and exposure to secondhand smoke may be possible reasons for the higher asthma prevalence among nonsmokers in urban areas. However, it is not clear from the study whether smoking causes more asthma symptoms. A reason for increased asthma prevalence among female smokers and ex-smokers may be attributed to their sensitivity toward smoking (41), but the increasing asthma prevalence among male nonsmokers needs further investigation. To reach valid conclusions, further studies with stratification by age will be beneficial.

According to our knowledge, the NPHS data set has not previously been analyzed as a comparative study of asthma prevalence among rural and urban residents. There were several advantages and disadvantages of using such a large database. A major limitation of using the NPHS was that no data were available on pulmonary function, methacholine challenge tests or allergy skin prick tests. This data set was not developed for asthma studies alone, but as a study of general health and chronic disease. Consequently, very limited information related to asthma was available. Some of the results may not have been presented due to low cell counts, because Statistics Canada recommends that estimates of unacceptable quality not be released (19). Another limitation of the study was the reliance on self-reporting of health professional-diagnosed asthma. The misreported or underdiagnosed cases can result in misclassification. Smoking was also self-reported, and the percentage of respondents who chose not to answer this question increased from $19.7 \%$ in cycle 1 to $28 \%$ in cycle 4 (Table 2). Smokers or ex-smokers might have chosen not to answer, and this could have resulted in nonrespondent bias.

There were several advantages to analyzing such a large national database. To reduce bias in the study, quality assurance measures were implemented. Interviews were conducted by experienced and trained interviewers to reduce potential interview bias. Nonresponse bias was minimized by implementing many strategies; a detailed description can be found in the documentation of the longitudinal survey by Statistics Canada (19).

As discussed earlier, the definition of self-reported 'health professional-diagnosed' asthma was used for the present study. Based on a survey of the literature, Torén et al (43) concluded that 'physician-diagnosed asthma' had a sensitivity of $64.3 \%$ and specificity of $94.3 \%$ compared with the selfreported asthma definition. In larger cohort studies, it is very expensive to conduct lung function and bronchial challenge tests. It becomes more inconvenient and costly when such tests are performed in longitudinal studies. As Pekkanen and Pearce (44) concluded, questionnaire surveys are cost effective and convenient, while sample size and response rates are high. However, supplementing the histamine challenge or lung function tests with a questionnaire can provide better understanding of asthma prevalence. It can be concluded that self-reported health professional-diagnosed asthma is a valid definition for studying the risk factors of asthma in large population-based studies.

\section{CONCLUSIONS}

We found opposing trends in asthma prevalence between men and women, as well as the existence of rural and urban differences in asthma prevalence. Stratified analysis according to smoking status and rural-urban location showed an increase in prevalence over time. The cause of the differences in asthma prevalence by sex, location and smoking status needs to be studied. More longitudinal studies are needed to determine the risk factors for the increase in asthma prevalence among women. The increase in asthma prevalence in male nonsmokers needs to be further investigated.

ACKNOWLEDGEMENTS: We thank the College of Graduate Research and Studies (CGSR) for providing financial support to Sunita Ghosh. We also thank Catherine Dick of Statistics Canada (Ottawa, Ontario) for her support with remote data access.

\section{REFERENCES}

1. Sears MR. The definition and diagnosis of asthma. Allergy 1993;48(17 Suppl):12-6.

2. Mannino DM, Homa DM, Akinbami LJ, Moorman JE, Gwynn C, Redd SC. Surveillance for asthma - United States, 1980-1999. MMWR Surveill Summ 2002;51:1-13.

3. Senthilselvan A. Prevalence of physician-diagnosed asthma in Saskatchewan, 1981 to 1990 . Chest 1998;114:388-92.

4. Senthilselvan A, Lawson J, Rennie DC, Dosman JA. Stabilization of an increasing trend in physician-diagnosed asthma prevalence in Saskatchewan, 1991 to 1998 . Chest 2003;124:438-48.

5. Variations in the prevalence of respiratory symptoms, self-reported asthma attacks, and use of asthma medication in the European Community Respiratory Health Survey (ECRHS). Eur Respir J 1996;9:687-95.

6. Barraclough R, Devereux G, Hendrick DJ, Stenton SC. Apparent but not real increase in asthma prevalence during the 1990s. Eur Respir J 2002;20:826-33. 
7. Dubois P, Degrave E, Vandenplas O. Asthma and airway hyperresponsiveness among Belgian conscripts, 1978-91. Thorax 1998;53:101-5.

8. Haahtela T, Lindholm H, Björkstén F, Koskenvuo K, Laitinen LA. Prevalence of asthma in Finnish young men. BMJ 1990;301:266-8.

9. Beasley R, Crane J, Lai CK, Pearce N. Prevalence and etiology of asthma. J Allergy Clin Immunol 2000;105:S466-72.

10. Public Health Agency of Canada, Canadian Institute for Health Information, Canadian Lung Association, Health Canada, Statistics Canada. Respiratory Diseases in Canada. Ottawa: Health Canada, 2001:122.

11. Boulet LP, Milot J, Beaupré A. [The mortality associated with asthma in Québec 1975-1985.] Union Med Can 1989;118:150-7.

12. Senthilselvan A. Trends and rural-urban differences in asthma hospitalizations in Saskatchewan 1970-1989. Can Respir J 1994;1:229-34.

13. Mo F, Robinson C, Choi BC, Li FC. Analysis of prevalence, triggers, risk factors and the related socio-economic effects of childhood asthma in the Student Lung Health Survey (SLHS) database, Canada 1996. Int J Adolesc Med Health 2003;15:349-58.

14. Chen Y, Dales R, Tang M, Krewski D. Obesity may increase the incidence of asthma in women but not in men: Longitudinal observations from the Canadian National Population Health Surveys. Am J Epidemiol 2002;155:191-7.

15. Chen Y, Dales R, Tang M, Krewski D. Sex-related interactive effect of smoking and household pets on asthma incidence. Eur Respir J 2002;20:1162-6.

16. Chen Y, Dales R, Krewski D, Breithaupt K. Increased effects of smoking and obesity on asthma among female Canadians: The National Population Health Survey, 1994-1995. Am J Epidemiol 1999;150:255-62.

17. Siracusa A, Kennedy SM, DyBuncio A, Lin FJ, Marabini A, Chan-Yeung M. Prevalence and predictors of asthma in working groups in British Columbia. Am J Ind Med 1995;28:411-23.

18. Rao JNK. Wu CFJ. Resampling inference with complex survey data. J Am Stat Assoc 1988;83:231-41.

19. National Population Health Survey, Cycle 4 (2000-2001) Household Component, Longitudinal Documentation. Ottawa: Statistics Canada, Health Statistics Division, 2000.

20. du Plessis VD, Beshiri R, Bollman RD, Clemenson H. Definitions of Rural. Rural and Small Town Canada Analysis Bulletin. Catalogue number 21-006-XIE. Ottawa: Statistics Canada, 2001;3.

21. Statistics Canada. 1996 Census Dictionary - Final Edition. $<$ http://www.statcan.ca> (Version current at March 12, 2008).

22. Statistics Canada. Postal Code Conversion File - June 2000 Postal Codes - Reference Guide. <http://www.statcan.ca> (Version current at March 12, 2008).

23. Feder M, Nathan G, Pfeffermann D. Multilevel modelling of complex survey longitudinal data with time varying random effects. Surv Methodol 2000;26:53-65.

24. Brogger J, Bakke P, Eide GE, Johansen B, Andersen A, Gulsvik A. Long-term changes in adult asthma prevalence. Eur Respir J 2003;21:468-72.

25. Skobeloff EM, Spivey WH, St Clair SS, Schoffstall JM. The influence of age and sex on asthma admissions. JAMA $1992 ; 268: 3437-40$.
26. Manfreda J, Becker AB, Wang PZ, Roos LL, Anthonisen NR. Trends in physician-diagnosed asthma prevalence in Manitoba between 1980 and 1990. Chest 1993;103:151-7.

27. Bjornson CL, Mitchell I. Gender differences in asthma in childhood and adolescence. J Gend Specif Med 2000;3:57-61.

28. D'Souza W, Lewis S, Cheng S, et al. The prevalence of asthma symptoms, bronchial hyperresponsiveness and atopy in New Zealand adults. N Z Med J 1999;112:198-202.

29. Tepper RS, Morgan WJ, Cota K, Wright A, Taussig LM. Physiologic growth and development of the lung during the first year of life. Am Rev Respir Dis 1986;134:513-9. (Erratum in 1987;136:800).

30. Woods RK, Burton DL, Wharton C. Asthma is more prevalent in rural New South Wales than metropolitan Victoria, Australia. Respirology 2000;5:257-63.

31. Ansari Z, Haby MM, Henderson T, Cicuttini F, Ackland MJ. Trends and geographic variations in hospital admissions for asthma in Victoria. Opportunities for targeted interventions. Aust Fam Physician 2003;32:286-8.

32. Ernst P, Cormier Y. Relative scarcity of asthma and atopy among rural adolescents raised on a farm. Am J Respir Crit Care Med 2000;161:1563-6.

33. Jarvis $\mathrm{D}$, Burney $\mathrm{P}$. ABC of allergies. The epidemiology of allergic disease. BMJ 1998;316:607-10. (Erratum in 1998;316:1078).

34. Hu FB, Persky V, Flay BR, Richardson J. An epidemiological study of asthma prevalence and related factors among young adults. J Asthma 1997;34:67-76.

35. Martinez FD, Cline M, Burrows B. Increased incidence of asthma in children of smoking mothers. Pediatrics 1992;89:21-6.

36. Vesterinen E, Kaprio J, Koskenvuo M. Prospective study of asthma in relation to smoking habits among 14,729 adults. Thorax $1988 ; 43: 534-9$

37. Torén K, Hermansson BA. Incidence rate of adult-onset asthma in relation to age, sex, atopy and smoking: A Swedish populationbased study of 15813 adults. Int J Tuberc Lung Dis 1999;3:192-7.

38. Godtfredsen NS, Lange P, Prescott E, Osler M, Vestbo J. Changes in smoking habits and risk of asthma: A longitudinal population based study. Eur Respir J 2001;18:549-54.

39. Eisner MD, Yelin EH, Trupin L, Blanc PD. Asthma and smoking status in a population-based study of California adults. Public Health Rep 2001;116:148-57.

40. Troisi RJ, Speizer FE, Rosner B, Trichopoulos D, Willett WC Cigarette smoking and incidence of chronic bronchitis and asthma in women. Chest 1995;108:1557-61.

41. Xu X, Weiss ST, Rijcken B, Schouten JP. Smoking, changes in smoking habits, and rate of decline in $\mathrm{FEV}_{1}$ : New insight into gender differences. Eur Respir J 1994;7:1056-61.

42. Langhammer A, Johnsen R, Gulsvik A, Holmen TL, Bjermer L. Sex differences in lung vulnerability to tobacco smoking. Eur Respir J 2003;21:1017-23

43. Torén K, Brisman J, Järvholm B. Asthma and asthma-like symptoms in adults assessed by questionnaires. A literature review. Chest 1993;104:600-8.

44. Pekkanen J, Pearce N. Defining asthma in epidemiological studies. Eur Respir J 1999;14:951-7. 


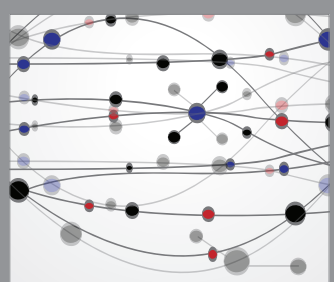

The Scientific World Journal
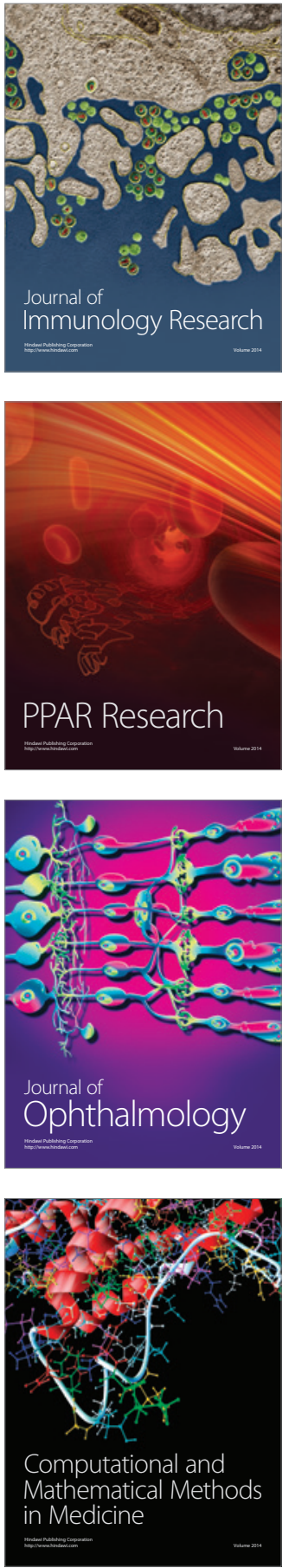

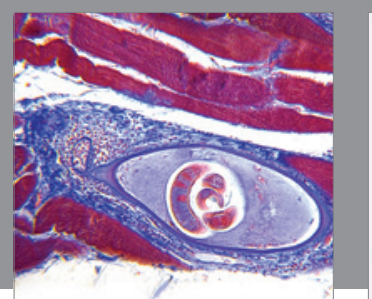

Gastroenterology Research and Practice

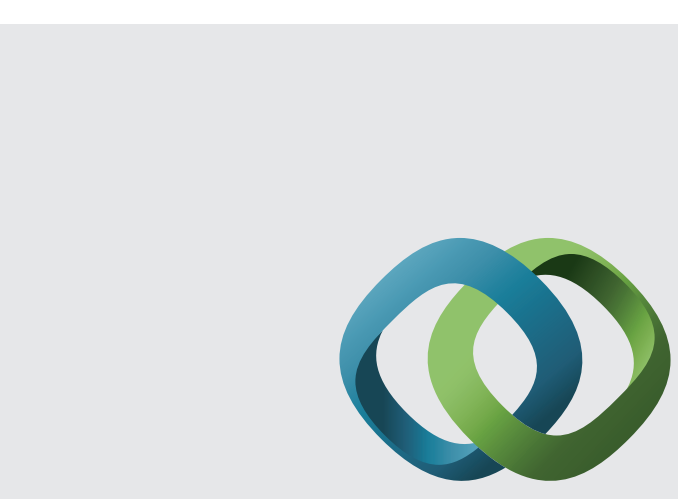

\section{Hindawi}

Submit your manuscripts at

http://www.hindawi.com
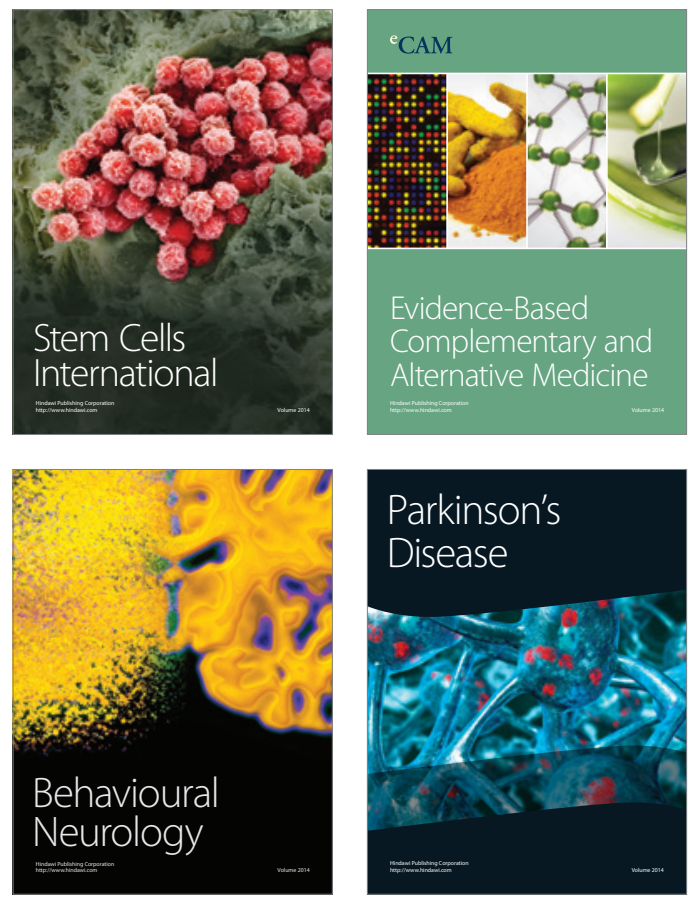
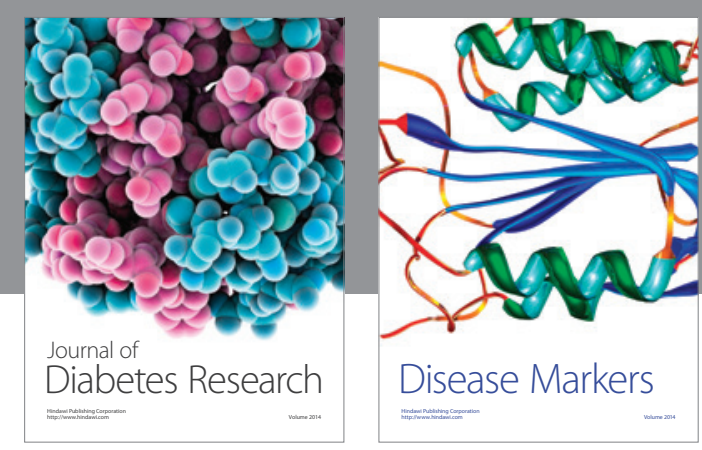

Disease Markers
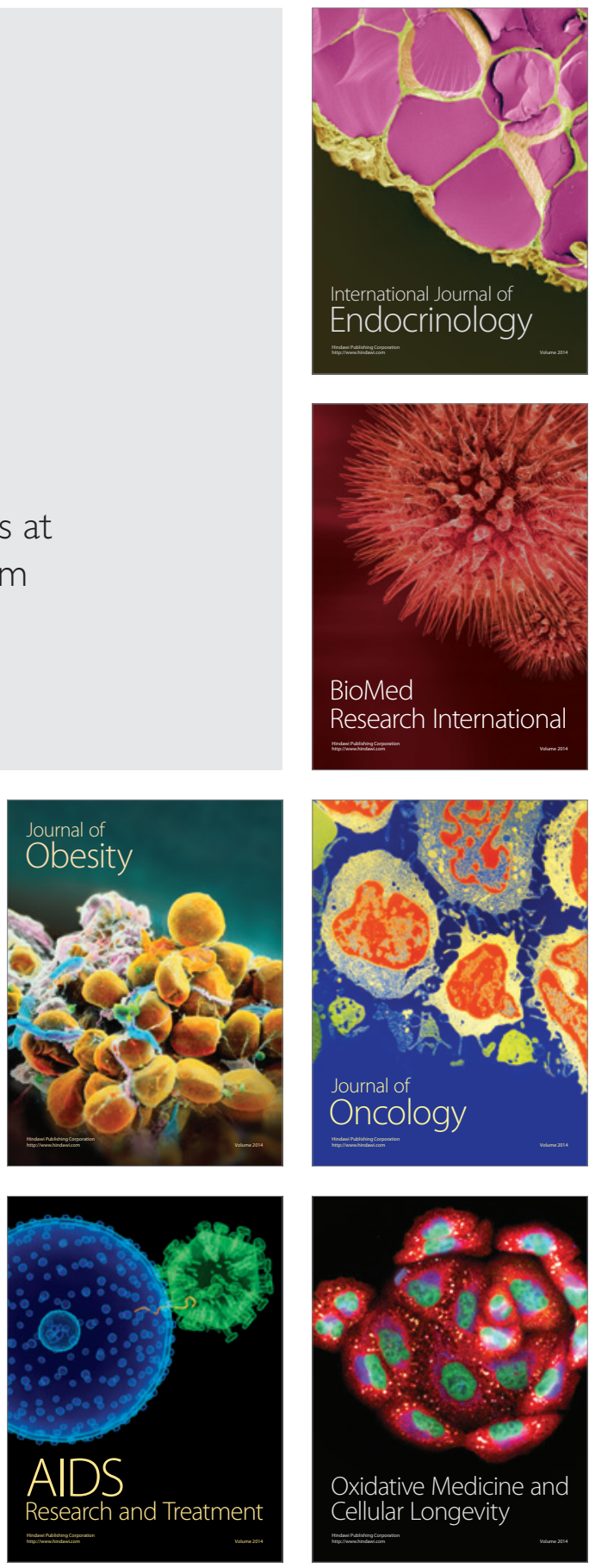